\title{
Becoming a Scientist: PhD Workplaces and Other Sites of Learning
}

\author{
Lynn McAlpine \\ Oxford Learning Institute, \\ University of Oxford, Oxford, UK \\ \& Faculty of Education, \\ McGill University, \\ Montreal, QC, Canada
}

\author{
Mahima Mitra \\ Department of Social Policy \& \\ Intervention, University of \\ Oxford, Oxford, UK
}

\section{Lynn.McAlpine@learning.ox.ac.uk}

Mahima.Mitra@spi.ox.ac.uk

\begin{abstract}
Doctoral students have often been described as apprentices engaged in workplace learning. Further, assumptions are frequently made in the literature about the common nature of such learning experiences, e.g., in the sciences, research-related practices are learned in a lab within the supervisor's program and team. A few recent studies of the science doctoral experience have challenged this view arguing such assumptions may overlook considerable variation. This longitudinal study, using frequently completed activity logs and an interview, reports on the researchrelated practices of twelve UK science doctoral students. The analysis, particularly of the logs, challenged some of the literature-based assumptions: students often chose to work in institutional offices, non-institutional sites and their homes rather than in labs; they did not necessarily engage regularly with a research team, nor were they necessarily engaged in a project directly linked to their supervisors'. That students chose not to work in traditionally assumed places suggests the importance of attending to: a) student agency, b) how research-related practices may be changing, and c) how sites of doctoral learning might need to be reconceived. As well, the findings suggest the value of non-traditional data collection methods in capturing variation in experience.
\end{abstract}

Keywords: Science doctoral experience, research-related practices, workplace learning, $\mathrm{PhD}$ workplaces

\section{Context: Learning Science}

In the literature, doctoral students have often been described as apprentices (Enders, 2005) learn-

Material published as part of this publication, either on-line or in print, is copyrighted by the Informing Science Institute. Permission to make digital or paper copy of part or all of these works for personal or classroom use is granted without fee provided that the copies are not made or distributed for profit or commercial advantage AND that copies 1) bear this notice in full and 2) give the full citation on the first page. It is permissible to abstract these works so long as credit is given. To copy in all other cases or to republish or to post on a server or to redistribute to lists requires specific permission and payment of a fee. Contact Publisher@InformingScience.org to request redistribution permission. ing research-related practices through observation, experience and interaction (aside from any required course work) in institutionally constituted workplaces. In this paper, research-related practices are conceptualized as the activities and interactions that support the conduct of doctoral research from initial thinking through to dissemination. These practices have been characterized in various ways (Pole, 2000; Morrison, Rudd, \& 
Nerad, 2011; Timmerman, Feldon, Maher, Strickland, \& Gilmour, 2013), but include reading, interaction with others to advance projects, feedback on work, thinking, in some cases collecting and maintaining samples of different kinds, analyzing, ethical decision-making - with the understanding that being a productive researcher and scholar requires different skills in different disciplines (Golde, 2005).

In this literature, assumptions are also frequently made about the common nature of such learning experiences, and how absence from these research cultures can circumscribe student learning (Deem \& Brehony, 2000). In the sciences in particular, the research team is characterized as a mutually supportive environment which meets daily so there may be more distributed problemsolving to deal with challenges; students spend the day at the bench to produce consistent useable results; the student's project is part of the supervisor's research program; the result of this workplace learning is stability and intellectual and pedagogic continuity (Delamont \& Atkinson, 2001; Hakala, 2009). Such descriptions reinforce assumptions about the common nature of doctoral research-related practices in the sciences, and their predominance in the literature speaks to their being of some value. However, Bowen and Roth (2007) and Cumming (2009) argue the need to capture more nuanced representations of science research-related practices (also see Gardner \& Gopaul, 2012). This suggests the value of looking at the day-to-day experiences of science doctoral students as they learn to do research, and provides the context for the present study.

\section{Goal}

This qualitative study reports an analysis of the research-related practices described by 12 science doctoral students in the UK. It examines their weekly patterns of work as well as their retrospective accounts of these over a period of 18 months as they learned, through their research-related practices, how to become independent researchers (Golde, 2005). The questions asked are:

1. What were students' overall experiences of learning to conduct doctoral research?

2. Where were they learning; specifically, in which places did they advance their researchrelated practices?

3. In what ways, if any, did the students demonstrate agency in choosing where to engage in and learn particular practices? And what practices were they engaging in?

4. What was the relationship, if any, between their research-related practices and their discipline/field?

\section{Conceptualizing Doctoral Work: Learning and Agency}

\section{Learning}

The starting point for this study is that doctoral-academic work can be conceptualized as a form of workplace learning, which it has been argued can shift the focus from the supervisor to other forms of pedagogic interaction (Malfroy, 2005). From this perspective, aside from coursework, doctoral-academic learning occurs through observation, experience, trial and error, and interaction with others, since we argue that "there is no separation between engaging in conscious thought - such as when participating in socially derived activities and interactions - and learning" (Billett, 2002, p.457). Generally, doctoral learning is characterized as taking place in institutional workplaces such as offices, labs and libraries (Middleton, 2010). If one accepts that "the socially shaped physical world ... exercises pedagogic properties projected through the physical environment and artefacts that students encounter" (Billett, 2009, p.40), then the institutional workplace - both its affordances (e.g., specialized equipment, supervisor) and constraints (e.g., meeting requirements for completion, dealing with inadequate equipment) - creates in unintended ways a 
tacit learning environment with learning outcomes less predictable and more variable than when learning is formally structured, e.g., in a course. Further, workplaces differ substantially in how they support learning (Billett, 2001). In fact, our own work has demonstrated the power of the institution in providing affordances and constraints for early career researchers. We have noted variations both across micro- and macro-level institutional units (McAlpine, Amundsen, \& Turner, 2013) as well as in how the same affordances and constraints were interpreted differently by individuals (McAlpine \& Lucas, 2011).

Of course, the assumption is that these institutional spaces for work are, in fact, where individuals conduct and learn to do research. Still, there is emerging evidence that suggests this may not consistently be the case. For instance, Pearson, Cumming, Evans, Macauley, and Ryland (2011) in an Australian survey of doctoral students reported that in the particular week surveyed only $42 \%$ had undertaken the majority of their doctoral activities on campus, with $33 \%$ working mostly at home and the remainder off-campus in other locations (with some variation by field). Thus, we argue that examining the spaces that students inhabit should provide insight into the ways they learn research-related practices.

\section{Agency within Identity}

We, like others studying science doctoral students (e.g., Holley, 2009; Felt, Fochler, \& Müller, 2012), are interested in how individuals constitute their scientific identities as they engage in doctoral-academic work. Our view of identity, 'identity-trajectory' (McAlpine et al., 2013), attends to individual histories; that is, how individuals represent the continuity of stable personhood over time and concurrently, a sense of ongoing change (Elliott, 2005). We are particularly interested in individual agency: how individuals undertake to advance their intentions and hopes in their work practices and their broader lives - whether or not successful. This interest in agency aligns well with the expectation of doctoral experience supporting the development of independence as a researcher (Gardner, 2008; Pilbeam \& Denyer, 2009).

Still, a focus on agency needs to recognize external influence since, for a realistic view of the relationship between agency and structure, individual intention needs to be investigated while not disregarding the structures that can support and constrain such agency (McAlpine \& Amundsen, 2009). Thus, while the work environment informally and in unintended ways creates a tacit learning environment, the degree to which an individual engages with this environment - that is, takes advantage of the affordances and manages the constraints - will influence the nature and quality of the learning. Further, we imagine individuals may make decisions not to engage in the institu-

tional workplaces given a certain set of constraints or access to other more conducive workplaces.

Billett (2001), in a study of three different non-academic workplaces, reported that individuals acted independently in ways inconsistent with work norms and practices - leading to the conclusion that participation is not passive or unquestioning. By exercising ongoing agency despite constraints, individuals have some ability to decide which aspects of the practices they encounter they will choose to engage in. The result is they can make or take for their own from what is encountered (Billett, 2006) given personal and work intentions. Still, while individuals have some ability to decide which aspects of the workplace practices they will engage in, and what their other options are, such agency does not imply that individuals are always successful in their attempts to achieve their intentions.

\section{Methodology}

This study is drawn from a longitudinal research program beginning in 2006 examining the experiences of doctoral students, post- $\mathrm{PhD}$ researchers and new lecturers in Canada and the UK (McAlpine \& Amundsen, 2011). While initially data were collected from social sci- 
entists, in 2010 we began studying natural scientists, the intention being, among others, to fill the gap in knowledge of their experiences. The research program draws on a qualitative narrative tradition which is used widely in the social sciences (Elliott, 2005). The underlying premise is that narratives represent constructions of identity (Sfard \& Prusak, 2005; Riessman, 2008). We collect narratives of experience and through successive readings of these narratives seek the essence, the meaning, of each individual's accounts (Elliott, 2005). This involves preserving and exemplifying connections between events, the influence of the passage of time in carrying the action forward, and showing the goals and intentions of individuals (Coulter \& Smith, 2009). Narrative research usually focuses on one individual, sometimes two or three, but like Thomson and Holland (2003) we have found looking across numbers of individuals useful since such analyses expand our understanding of the variation both within and across individuals. Lastly, much of the qualitative research addressing academic experience draws on a single interview which captures retrospective accounts and/or experience at the time of the interview. In contrast, longitudinal studies of academic experience like ours, which are relatively rare, make it possible to document concurrently consistencies as well as changes in experience and intention (Eby, Butts, \& Lockwood, 2003).

\section{Participants}

The 12 science doctoral students were from two different UK research universities; five females and seven males, representing computing, engineering and the biosciences. While we focused on all the disciplines under the broad umbrella of the STEM (Science, Technology, Engineering, Mathematics) sciences when sending out our call for recruitment, the subject fields in the final sample (indicated above) comprise those that participated in our study.

\section{Data Collection and Analysis}

We collected multiple narratives of experience over time, beginning with an initial biographic questionnaire (that captured information such as age, field, role, prior work experience, possible future careers). This questionnaire, along with all other tools for data collection (except the interview which was face-to-face), was drafted in Microsoft word and sent out as an electronic file attachment via email, and comprised a mix of open- and close-ended questions. Bearing in mind the prevailing view that science students would be part of a team, individuals were asked, among other things, to describe the composition of their research team, if they belonged to one. The biographic questionnaire was followed by activity logs about a particular week. These logs were completed 5-6 times over a year (depending on the average response time of each participant) and captured their primary work spaces in that week; the experiences, activities, relationships, interactions and challenges of the particular week, as well as their overall mood over the course of the week. Next, a pre-interview questionnaire provided a retrospective view of the year that had passed since they began completing logs. Last, an interview elicited more detail about the earlier narratives (all data were read prior to the interview) as well as explored new areas, before the annual data collection cycle began again. This analysis draws on one complete year and the following half-year given our desire to collect enough logs from each individual to capture consistency as well as variation in patterns of work and learning.

We followed a thematic analysis common in narrative research, "keeping a story intact by theorizing from the case rather than from component themes across cases" (Riessman, 2008, p.53). This is different from thematic analyses common in other research traditions where findings are presented and organized first by theme rather than by individual (for examples, see Miles \& Huberman, 1994). In this study, we were looking for patterns related to research-related practices and the spaces in which they were conducted. We drew on the various documents described 
above, ranging from 9-15 documents per individual, including one interview transcript (average number of documents: 12 ).

We initially read and coded all narratives for two individuals and compared coding decisions; any discrepancies were dealt with. We then continued coding, checking portions of each other's coding periodically, again reconciling any pertinent issues and recoding as necessary. The procedure for coding was as follows. Each coder read through all the narratives for an individual in chronological order in order to code while still maintaining a biographic awareness. Then, for each narrative, any text relevant to the experience of work was identified: a) physical spaces (both institutional and non-institutional) where individuals reported working; b) the nature of the researchrelated activity; c) their explanation for why these sites were chosen; and d) the material and social resources and constraints in each site and how the individual managed them. These different aspects of their learning experiences would often co-occur in an individual's narrative as in this account from Catherine's $\log 4$ (note that all the names as used in this paper are pseudonyms chosen by participants). Catherine was one of the two participants who reported working mostly in the lab, and she consistently reported difficulties which slowed her progress despite her best efforts:

The current DNA extraction protocols [research-related practice] used by my lab [physical space] do not give clean enough DNA [constraint] to perform a technique I need for one of my experiments [her doctoral research]. Also, as there are more people in my lab than previously the equipment is often not free [constraint] which has caused several delays recently. Tried multiple different procedures over about 3 days which was a significant investment of time [agency] but thus far have not found any significant improvement in quality, so will have to try again next week. To use some pieces of equipment I ended up staying very late in the evening [agency].

We excluded the following when coding:

- $\quad$ spaces related to other academic work, e.g., teaching and supervision, since the focus of the analysis was research-related activities;

- social and personal activities for which no explicit statement of impact on research activities was made; and

- past and future spaces and activities since the focus was their learning during the data collection period.

Once all data for an individual had been analyzed, the identified text selections were brought together to generate a researcher perspective on the cumulative experience. A final step was a cross-individual comparison to move beyond the particulars of any one individual towards an understanding of common patterns of workplace learning. This involved moving back and forth between each individual's experiences to construct a cumulative representation of the learning related to research-related practices.

\section{Findings: Science Doctoral Student Research-Related Work Practices}

We begin by overviewing the participants briefly, and provide three cameos to demonstrate individual variation. Then, we address each of the research questions interweaving discussion with results. 


\section{Who They Were}

Despite the common assumption that science doctoral students tend to be younger and go directly from undergraduate/master's to $\mathrm{PhD}$ (Pearson et al., 2011), in fact, eight of the 12 had prior work experience of varying degrees (see the Appendix for brief introductions to each participant). Thus, they ranged in age when starting the degree from 22 to 45, with most under 30. This distribution, varying from early to mid-adulthood, is relatively similar to the overall age range of science students enrolled in the two universities (primarily 20-40 years; with very few over 40), as were other demographic characteristics: a) of the five females, three were in the biosciences, the two others in engineering and computing; and b) seven were international students - four with English as another language. Of the 12, nine had funding (and later, an additional participant moved from self- to partial-funding). In looking beyond their doctoral work, 11 noted family and eight a partner as significant, and at least seven engaged in a range of physical and/or creative activities. When they began participating (September, 2011), four were in their $1^{\text {st }}$ year, three each in their $2^{\text {nd }}$ and $3^{\text {rd }}$ years, with the remaining two in the $4^{\text {th }}$ and $5^{\text {th }}$ years.

The three cameos below provide a sense of the individual variation in experience. Tom experienced some ups and downs but generally had a positive experience of doing and learning to do research-related activities over the 18 months.

Tom, $2^{\text {nd }}$ year, worked principally in his office (high-performance computational biology), lab (molecular biology where the equipment was) and home (writing where he wouldn't be disrupted). He also worked at another university for several weeks during this period after receiving a bursary to conduct additional lab experiments relating to his research there. His mood, over 18 months of participation in our study, varied from feeling cheerful, "just getting along" to "slightly stressed" (e.g., at not 'fixing' the animals, i.e. preparing samples for lab experiments). He reported procrastinating sometimes and had to set goals to complete important tasks. He noted he should be reading all the time, though didn't always manage this, and also worked on drafting articles, noting his belief that publications were representative of how productive he was as a scientist. He also passed his upgrade (waiting for the viva was stressful), assembled sequence data, made phylogenetic trees, and did data 'wrangling' in Excel (all of these are tasks within evolutionary developmental biology). He noted too many tasks and not enough time. He also trained master's and undergraduate students in molecular biology laboratory techniques e.g. embryo manipulation, molecular cloning and antibody staining. Tom had come with his own project idea so did not take on one provided by his supervisor. Still, two of the six in his research team worked in similar areas, and "I do quite a bit of my socialising within the lab group ... so teaching, research project, and lab experimental work are all sort of hand in hand and they're definitely taking up the most of my time." He also enjoyed a positive relationship with his supervisor and had won additional funds. Still, he felt constrained by the 3-year time limit: "Getting everything done in 3 years, especially when working with animals that spawn for only a few months a year, is pretty intense." Throughout, "my work has a major bearing on my emotions." Fortunately, his girlfriend and his sports activities helped him in this regard. At the end of the 18 months, Tom was preparing to submit his thesis and contemplating taking up a job offer from one of his collaborator laboratories in the Far East.

In contrast, 13196 had a more constant experience of pressure and isolation.

$13196,5^{\text {th }}$ year computing sciences, consistently reported working at home; in fact, on another continent. For 13196, data computation and analysis had been running hand-inhand with thesis writing primarily due to part-time work commitments, family commitments and substantial delays in achieving results that would be considered significant. He 
was doing fieldwork and writing his thesis when he began his participation in our study, and was determined to finish, moreover, had quit his part-time job to ensure this was the case. He consistently felt isolated while still having email and Skype conversations with his supervisors, noting "it's positive if you can use the isolation to concentrate on a problem and really work on it, but ... it can be a negative because of feelings of loneliness ... and [the] opportunity to ... procrastinate ... that, if your supervisor were watching you, ... wouldn't be allowed to happen." He missed department life and had to deal with problems related to his extensions, e.g., expiration of university card, which caused loss of access to email and computer systems, library, and remote access to research databases. $\mathrm{He}$ also found his family and domestic responsibilities disruptive and distracting. Further, coming with his own project, the other students did not share his interests. So while "they've been encouraging me ... sending me new information that might be relevant to my thesis ... they can't help me at all. So, my relationship with the other doctoral students is ... tenuous at best." As well, over time, he felt increasingly pressured by his supervisors and the department to finish as he had received all the extensions he could: "I am terrified of looking at my email every morning." Still, having seen his thesis change radically over the five years, he felt that "good science takes as long as it takes, and I am being forced by the calendar to submit before I am ready. I hate my life." Near the end, he was "feeling physically ill; worrying that I have only one week left to submit my thesis." Nevertheless, 13196 submitted and completed his degree.

Lastly, Kadyna's experience was largely but not always positive as a result of the constant support provided by her husband and supervisor.

Kadyna, $2^{\text {nd }}$ year civil and environmental engineering, spent equal time working in her office and home (especially after recent surgery), and at other locations while travelling for conferences and meetings. She spent most of her time testing and amending hydrological models to predict water movement, writing documentation and software routines for building these models, making calculations and verifying predictability, and debugging the related computer code she was writing. Her moods shifted in line with the progress she made - varying from confident, engaged and satisfied when her model gave valuable results, to anxious and frustrated when the model didn't work or her code needed debugging. In addition to her $\mathrm{PhD}$ work, she had a part-time Research Assistant job, two national council-funded projects, and did undergraduate teaching. She found writing papers "the most difficult part of research, as I am not a native-English [speaker]" and seemed especially encouraged by any validation of her work received through her supervisor and others. Her husband, who worked in a similar field, was a source of constant emotional and intellectual support, her most important relationship: "he was extremely important at the beginning when I decided to start my $\mathrm{PhD}$, and [now] ... because ... when we have these chats about work, I run to the computer and try something that he inspires me to do." She also received support from other doctoral students at work: "I often have meetings, even coffee breaks, with them, and that is a really interesting moment where we're talking about experiments ... what we are going to do, and grab some ideas [off each other]". Finally, Kadyna's supervisor was central in maintaining her motivation: "Every time I [feel] stressed and anxious because I'm not getting the result I want ... he always calms me down and says, "No worries - everything is going to be okay"'.

These cameos thus provide a snapshot view of the doctoral life of some of our participants: who they were, what work practices they were engaged in, and what the form and nature of support available (or not available) to them was. We now present a thematic analysis of the data by addressing each of the four questions raised above, in turn. 


\section{Question 1: What were Students' Overall Experiences of Learning to Conduct Research within their Doctoral Work?}

The three cameos above demonstrate that engaging in doctoral work and more specifically in research-related practices was not only an intellectual journey but also an emotional series of ups and downs. Kadyna, for instance, reported successively over the 18 months being "inspired, satisfied, struggling, anxious, frustrated and enthusiastic" (when dealing with coding problems). Catherine was "struggling, stressed, more confident, unhappy, positive" and then "stressed" again as she was alternately not successful and then successful with her experiments. Occasionally, negative emotion was unrelenting; for instance, 13196 was almost constantly reporting negative emotions in relation to the university completion deadline: "isolated, stressed, hate my life, physically ill". He only felt somewhat relieved when he did not receive deadline reminders. RP was relatively unusual in nearly always reporting positive feelings in relation to his research progress each week: "wonderful, excited, inspired, and highly energetic."

Notably, negative emotions sometimes resulted from balancing research interests with the expectation of completing in three years. Similar to 13196 and Tom, Apollo described this ongoing insecurity:

The area of research ... it's not the most promising area ... and when I started ... I wanted to do ... the thing which appeals to me the most, not the one which seems to provide me [a secure] future. So ... I do not know for sure if I can finish in three years and eh ... the insecurity about funding for a possible and very probable, fourth year is ... the cause for this insecurity.

Writing was also often experienced negatively (e.g., Fred, who was otherwise nearly always positive, was consistently frustrated at his inability to write effectively). Travel too was a disruption (e.g., Apollo working at night and drinking coffee for the caffeine to keep him going as he dealt with jetlag). A number who noted the negative impact of research-related work offset this impact through social contact and other kinds of engagement, e.g., sports. Sophie (a male) exercised and played sports regularly (football, karting) to avoid getting a backache from sitting in front of his computer every day. Rumi attended tango and meditation each week to stay physically fit and increase her concentration at work.

These experiences resonate with Neumann's (2006) study of experienced researchers and Hopwood and Paulson's (2012) study of doctoral students. Neumann characterized experienced researchers' emotional experiences as extremely varied. While they sought and had occasional peak positive experiences of deep involvement, joy and a sense of accomplishment in conducting research, they also experienced long periods of "mucking about" which they described as disastrous, frustrating, upsetting, and painful. Hopwood and Paulson examined the toll that fatigue and stress took on doctoral students. We concur with the conclusions of both these studies: the intertwining of emotions with intellectual thought is often overlooked, yet is essential to undertaking research-related activities. More careful attention to this aspect of becoming a researcher could enhance the development of resilience (McAlpine \& Amundsen, 2011) necessary in a culture sometimes characterized as one of rejection.

\section{Question 2: Where were Students Learning; specifically, in which Places did they Advance their Research-Related Practices?}

Regardless of where they were in their doctoral progress, the majority regularly worked in a number of different places: Apollo in his home, office and at conferences; Tom in his office, lab, 
home, and other research unit; Tulip in the British Library and her office. Still, a few worked relatively consistently in only one place: Catherine in the lab, 13196 at home.

Individuals also changed where they worked over time. These shifts could be related to their research activities as they advanced their projects. Apollo, $1^{\text {st }}$ year, for instance, noted doing more reading earlier in the period than later. And, near the end of the degree, nearly all participants reported increasing amounts of time spent on writing their theses. Still, such changes in work place were not necessarily related to their research, but rather to how their research was situated within the rest of their lives, e.g., Tom working more in the office this year than last since he no longer had teaching duties; Kadyna spending more time at home at one point due to recent surgery.

Strikingly, in examining references to institutional spaces, there was more work reported in offices than labs; in fact, only Tom and Catherine made reference to lab use. (Of the 12 participants in this study, 10 reported having laboratories as work spaces but not using them; this included four who mentioned a computer lab. In other words, reference to a lab need not imply a wet lab or one with specialized equipment). Labs, of course, provide material resources that cannot be found elsewhere. And the maintenance of these material resources was seen as critical, e.g., Catherine struggled because reagents were faulty and batches of organisms did not arrive on time. In general, the material resources provided by offices were not as critical as those in labs. If offices created particular material spaces it was largely in terms of increased computing power or easier access to large data sets - though a major value was also being close to the supervisor. Interestingly, there was no reference to spending time in libraries, institutional spaces which at one time were central to much research work; the absence of reference to this is probably due to new technologies which have converted physical access into virtual ones.

Moreover, it was clear that non-institutional spaces were as frequently referred to as institutional ones. Non-institutional workplaces included conferences, hotel lobbies, the bed, home, and other research centres. The reports of working at home resonate with Kuntz's (2012) finding that the home is increasingly a site of academic work. Further, the results confirm the assertion that the prevailing view of science practices as lab-based may need reframing (Bowen \& Roth, 2007; Cumming, 2009). More generally, the results raise questions about the nature of doctoral learning, which assumes that science doctoral students engage in research-related activities in common institutional spaces.

\section{Question 3: In what ways, if any, did the Students Demonstrate Agency in Choosing where to Engage in and Learn Particular Practices? And what Practices were they Engaging in?}

While question two addressed only the physical locations in which the students worked, this question takes up a more complex issue: the ways in which students were agentive in choosing which places to work in order to best meet their needs in undertaking different research-related activities. A defining feature of their choice of workplace was the material and social resources on offer and their individually varied responses to these. So we begin by demonstrating the variation in their decisions related to the resources attached to particular workplaces and activities, before exploring their specific use of institutional and non-institutional spaces.

\section{Agency, resources, and research-related activities}

Individuals described physical spaces as affording different material and social resources, and chose their workplaces based on what best suited the research-related activities they wanted to engage in. What they were doing, or learning to do, therefore influenced, as well as was influenced by, the space they chose to work in on a day-to-day basis. For instance, Tulip in zoology went to her office two days a week for supervisory and postdoc meetings, but otherwise worked 
in the British Library (and sometimes her home) doing computational work and writing. She noted in particular how the British Library imposed material and social constraints that 'forced' her to stay focused and not become distracted by talking, eating or drinking. Others noted the need to be at home to write since this space was less social than the institutional spaces (e.g., when writing, Kadyna wanted quiet and Fred a place to pace up and down).

The need for focus was shared by others, though leading to different decisions: TDB preferred his computer and "comfortable desk" in his institutional office in order to be more focused than at home. Rumi, on the other hand, preferred to work at home because it gave her the flexibility to continue to work as long as she wanted. SA worked at home when she needed to do mundane, repetitive tasks for which the home environment was more comfortable and relaxed (she could listen to music while working) while Sophie worked equally at home in addition to his departmental office because of the ability to work remotely, using his laptop. RP preferred jumping into the shower when thinking about new ideas.

\section{Institutional spaces and social resources}

Despite choosing non-institutional spaces for some work, all the students worked in institutional workplaces which incorporated distinct material resources, thus, e.g., in the lab, specialized equipment; in the office, desks, chairs and computers. Further, these spaces were inherently social which carried both strengths and weaknesses. In some cases, the social environment was seen as enhancing learning substantially. Tom, as noted earlier, reported not just enjoying working with his lab mates and his supervisor, but also meeting members of the team socially. Others described social spaces that, while positive, were not productive in furthering their work, as the team did not fully understand the issues (note 13196 earlier). And, the inherently social aspect of the workplace could be experienced negatively due to the interactions and practices within that space. Tom reported that training a particular new student who required repetitive instructions and an unusually high degree of supervision was a "time sink", taking time away from his own work. Catherine experienced negative feelings from spending much of her time in the lab without achieving much success. Recognizing the need for positive social interactions to sustain her motivation, she organized weekly informal coffee sessions to discuss both personal life and academic progress. Similarly, 13196, who also acknowledged being socially isolated, offset the isolation by, for instance, having weekly Skype meetings with his supervisors to follow up on his written reports, and also participating virtually in the journal club organized by his supervisors.

As well, the work students reported doing did not necessarily involve a team, though Sophie and Fred, like Tom, considered their teams and/or supervisors very supportive and important. Many others (e.g., Apollo, Fred, and RP) were engaged in solitary computational work which involved them modelling and testing simulations and debugging software routines. Several in teams noted that their work was not connected to that of others in a team (e.g., Apollo, Catherine and Fred). In fact, five of the 12 had chosen their own projects so had not taken on a part of their supervisors' research program for their own research. This finding suggests that the prevailing view of science practices as revolving around a research team (Delamont and Atkinson, 2001) is not always pertinent.

Overall, we concluded that institutional social spaces could be: a) avoided to do work that required solitude; b) viewed negatively due to local practices and interactions; or c) viewed positively and sought out. This awareness of and preference for seeking different types of spaces in relation to different research-related activities provides evidence of the ways in which individuals were agentive in choosing the degree to which they wanted to engage in participatory work practices (Billett, 2001). Further, it suggests that characterizing research-related practices as connected to a specific discipline/field results in a failure to document the richly textured and varied 
learning experiences that individuals are actually engaged in (also noted by Leon-Beck \& Dodick, 2012) - an issue we take up in more detail in question 4.

\section{Non-institutional spaces, material and social resources - real and virtual}

Individuals also often worked in non-institutional spaces, choosing these spaces in relation to what they wished to accomplish. Further, they reported drawing on colleagues beyond any team they were involved in, and beyond the university via conferences, the web, and list servs. Some of these participatory work spaces were created in non-institutional spaces that either did not occur regularly, e.g., Apollo at conferences talking about maths issues, or could be considered by some as tools rather than places, e.g., Sophie communicating online with others about research challenges and solutions. In this regard, Sophie was like the academics studied by Menzies and Newsome (2007) who reported that new technologies created material and social resources that influenced the ways in which individuals engaged in research-related activities. Still, the influences were not always positive (Menzies \& Newsome, 2007): a) 13196 fearing opening his email in case there was another note about the impending deadline; b) Tom needing to embargo his use of the internet since it was a procrastination strategy; and c) Rumi worrying about emails that "take too much time ... I am often distracted".

These virtual material and social resources, often supported by the institution, can open up new opportunities, but at the same time can lead to less need or desire to draw on institutional spaces, and less face-to-face interaction with local colleagues. Overall, the sense was that physical proximity was less influential in the learning process than previously reported in the literature (e.g., Deem \& Brehony, 2000; Walsh, 2010), at least for some students. In other words, individuals were agentive in: a) choosing particular sites to do particular kinds of research-related practices; b) avoiding some institutional spaces because they are not socially conducive; and c) using extended and virtual social networks to manage challenges and develop participatory research practices.

In our view, the fact that everyone drew on the material resources offered by computers (and through them a vast set of social resources) suggests reasons why institutional spaces were not consistently used. Many research-related practices no longer require institutional locations since new technologies make it easy to have a virtual set of resources including access to extended academic relationships (Kuntz, 2012). Further, new technologies are expanding the range of research-related practices, e.g., modelling capacities exist that did not earlier. In other words, like those in non-academic organizations (Engstrom, 2004), to an increasing degree, work practices are moving beyond organizational and geographical boundaries. Nevertheless, institutional workplaces still played a role: a) some practices required special tools only available in the institution, e.g., lab equipment, super-computers; and b) face-to-face access to some institutional affordances, e.g., supervisor, research team, invited institutional work.

\section{Question 4: What was the Relationship, if any, between Students' Research-Related Practices and their Discipline/Field?}

On the whole, we concluded that those in computing sciences, theoretical physics, engineering, inorganic chemistry, materials and zoology, engaged in forms of computation, often involving statistical modelling. They were engaged to a considerable extent in what Duffin and Simpson (2005) in their study of mathematics doctoral students, characterized as independent (and isolating) computational work, with the goal to learn to guess in a disciplined way - referred to by experienced mathematicians as 'disciplined guessing' (Geraniou, 2010). 
At the same time, we do not want to create the impression that computational work constituted all their research-related practices. In fact, our insight was that computational work was only one aspect of their research practices; for instance, TDB used specialized equipment, transition electron microscopy, to see how defects form in a particular material, as well as for 'editing' the resulting images (removing noise), before analysing the resulting data computationally, looking for trends to theorize models. And, as SA noted:

When I was younger, I always thought I'd be much more the kind of person who would be out in the field collecting samples, but it really actually doesn't appeal to me in retrospect. I actually prefer sitting at the computer and coming up with real analyses and seeing graphs and actually identifying the bigger picture's patterns.

It was evident that the fields individuals were in did not designate their practices. For instance, Catherine and Tulip, both $2^{\text {nd }}$ year and in zoology, engaged in different activities - Catherine testing organisms and Tulip doing statistical modelling. Further, an individual's research practices could be quite varied; so, Tom, $2^{\text {nd }}$ year biology, reported doing computational and 'wet' lab work as well as writing.

The results highlighted the variability in research-related activities within the same discipline/field; they were neither uniform nor consistent. This suggests that we need to be cautious about characterizing the relationship between discipline/field and research-related practices in monolithic ways, as has often been the case (e.g., Delamont \& Atkinson, 2001; Hakala, 2009). Leon-Beck and Dodick (2012) are noteworthy in this regard, describing, for instance, three types of ecological experiments: the lab where one can control independent variables but the results are unrealistic; the field which is more realistic but more difficult to control variables; and the natural where there is the most 'realism' but no control. We agree with Leon-Beck and Dodick (2012) that methodological differences among different branches of the same science make it impossible to superimpose general learning models.

\section{Conclusion: Institutional and other Sites of Learning - Re-Conceptualizing Workplace Learning}

We return now to our starting point. Earlier studies in the sciences (Bowen \& Roth, 2007; Cumming, 2009) directed us to look more closely at the day-to-day nature of the research-related practices of science doctoral students. Doctoral students have often been described as apprentices (Enders, 2005): individuals learning research-related practices through observation, experience and interaction in institutionally constituted workplaces such as offices, labs and libraries (Middleton, 2010). Still, there is emerging evidence that suggests this may not consistently be the case (Pearson et al., 2011). We were also interested in how students enacted their agency given the expectation that doctoral experience supports the development of independence as a researcher (Gardner, 2008; Pilbeam \& Denyer, 2009).

The results of the study, using multiple data collection points rather than the more common approach of a one-time interview or survey, clearly demonstrated student agency, as individuals often chose where they worked in relation to what they wanted to accomplish - with one individual's rationales sometimes contrary to another's. In this manner, they were able to adjust, on a day-to-day basis, the material and social resources on offer in ways that met their own learning needs - though not always completely successfully (McAlpine et al., 2013).

In making these choices, we found them selecting both institutional and non-institutional spaces. They often chose institutional spaces for the social resources on offer related to particular research-related practices - especially when they found these supportive. In choosing to work away from institutional workplaces (though not all had this as a choice), students were often seeking 
solitude to accomplish a particular activity. However, solitude was not always the goal in working away from the institution; they sometimes sought out and engaged in virtual social resources during these times.

In other words, there was plentiful evidence that students were not infrequently learning largely in physical isolation from most institutional social and material resources; that is, while engaging in conscious thought in relation to socially derived activities (Billett, 2001), they were doing so virtually. Thus, the findings suggest a need to broaden our view of doctoral workplace learning to include non-institutional sites of learning, and material and social resources that are available virtually. (We acknowledge that there are programs that intentionally seek out partnerships or internships for doctoral students outside the academy, but these are institutional pedagogies, not the individual choices we are referring to here.)

While access to virtual resources expands the range of learning opportunities, absence from the physical workplace shuts out unpredictable and occasional observations, or spontaneous but sometimes powerful interactions that have traditionally been conceived as part of the doctoral learning environment. This raises interesting questions about how engagement in socially derived activities that are physically distant may significantly impact on what is learned and not learned.

For instance, we wonder in what ways absences from the institutional workplace may lead to gaps in learning given the reduced opportunity to participate in research-related practices that are occasional in nature, e.g., on-the-spot ethical decisions-making (de Vries, Anderson, \& Martinson, 2006). Still, we acknowledge that being in the institution does not guarantee such opportunities either (Holley, 2009).

We conclude that we can no longer assume that 'workplace learning' is situated in institutional spaces - new technologies are disrupting earlier forms of learning as they create new (Currie \& Eveline, 2011). This expansion of learning beyond traditional institutional workplaces calls us to re-think how to better represent doctoral 'learning-to-work' as co-constituted by both institutional and non-institutional sites of learning with the agency expected of emerging researchers evident in their choices as to where and how to work.

\section{References}

Billett, S. (2001). Learning through work: Workplace affordances and individual engagement. Journal of Workplace Learning, 13(5), 209-214.

Billett, S. (2002). Workplace pedagogic practices: Co-participation and learning. British Journal of Educational Studies, 50(4), 457-481.

Billett, S. (2006). Relational interdependence between social and individual agency in work and working life. Mind, Culture and Activity, 13(1), 53-69.

Billett, S. (2009). Conceptualizing learning experience: Contributions and mediations of the social, personal and brute. Mind, Culture and Activity, 16(1), 32-47.

Bowen, M., \& Roth, W-M. (2007). The practice of field ecology: Insights for science education. Research in Science Education, 37, 171-187.

Coulter, C., \& Smith, M. (2009). The construction zone: Literary elements in narrative research. Educational Researcher, 38(8), 577-590.

Cumming, J. (2009). The doctoral experience in science: Challenging the current orthodoxy. British Educational Research Journal, 35(6), 877-890.

Currie, J., \& Eveline, J. (2011). E-technology and work/life balance for academics with young children. Higher Education, 62(4), 533-550.

Deem, R., \& Brehony, K. (2000). Doctoral students' access to research cultures - are some more unequal than others? Studies in Higher Education, 25(2), 149-165. 


\section{Becoming a Scientist}

Delamont, S., \& Atkinson, P. (2001). Doctoring uncertainty: Mastering craft knowledge. Social Studies of Science, 31(1), 87-107.

de Vries, R., Anderson, M., \& Martinson, B. (2006). Normal misbehaviour: Scientists talk about the ethics of research. Journal of Empirical Research on Human Research Ethics, 1(1), 43-50.

Duffin, J., \& Simpson, A. (2005). Cognitive empathy and the transition to independent graduate study in mathematics. Educational Studies in Mathematics, 58(1), 121-135.

Eby, L., Butts, M., \& Lockwood, A. (2003). Predictors of success in the era of the boundaryless career. Journal of Organizational Behaviour, 24(6), 689-708.

Elliott, J. (2005). Using narrative in social research: Qualitative and quantitative approaches. London, UK: Sage.

Enders, J. (2005). Border crossings: Research training, knowledge dissemination, and the transformation of academic work. Higher Education, 49(1-2), 119-133.

Engstrom, Y. (2004). New forms of learning in co-configuration work. Journal of Workplace Learning, 16(1-2), 11-21.

Felt, U., Fochler, M., \& Müller, R. (2012). Biography and/or career? Young researchers' perspectives on knowing and living in contemporary research. University of Vienna: Department of Social Studies of Science.

Gardner, S. (2008). Fitting the mold of graduate school: A qualitative study of socialization in doctoral education. Innovative Higher Education, 33(2), 125-138.

Gardner, S., \& Gopaul, B. (2012). The part-time doctoral student experience. International Journal of Doctoral Studies, 7, 63-78.

Geraniou, E. (2010). The transitional stages in the $\mathrm{PhD}$ degree in mathematics in terms of students' motivation. Educational Studies in Mathematics, 73(3), 281-296.

Golde, C. (2005). The role of the department and discipline in doctoral student attrition: Lessons from four departments. Journal of Higher Education, 76(6), 669-700.

Hakala, J. (2009). Socialization of junior researchers in new academic research environments: Two case studies from Finland. Studies in Higher Education, 35(5), 501-516.

Holley, K. (2009). Animal research practices and doctoral student identity development in a scientific community. Studies in Higher Education, 34(5), 577-591.

Hopwood, N., \& Paulson, J. (2012). Bodies in narratives of doctoral students' learning and experience. Studies in Higher Education, 37(6), 667-681.

Kuntz, A. (2012). Reconsidering the workplace: Faculty perceptions of their work and working environments. Studies in Higher Education, 37(7), 769-782.

Leon-Beck, M., \& Dodick, J. (2012). Exposing the challenges and coping strategies of field-ecology graduate students. International Journal of Science Education, 34(16), 2455-2481.

Malfroy, J. (2005). Doctoral supervision, workplace research and changing pedagogic practices. Higher Education Research and Development, 24(2), 165-178.

McAlpine, L., \& Amundsen, C. (2009). Identity and agency: Pleasures and collegiality among the challenges of the doctoral journey. Studies in Continuing Education, 31(2), 107-123.

McAlpine, L., \& Amundsen, C. (2011). Supporting the doctoral process: Research-based strategies for doctoral students, supervisors and administrators. Amsterdam: Springer.

McAlpine, L., Amundsen, C., \& Turner, G. (2013). Identity-trajectory: Reframing early career academic experience. British Educational Research Journal, 40(6), 952-969.

McAlpine, L., \& Lucas, L. (2011). Different places, different specialisms: Similar questions of doctoral identities under construction. Teaching in Higher Education, 16(6), 695-706. 
Menzies, H., \& Newsome, J. (2007). No time to think. Time and Society, 16(1), 83-98.

Middleton, S. (2010). Rhythms of place: Time and space in the doctoral experience. In M. Walker \& P. Thomson (Ed.). The Routledge Doctoral Supervisor's Companion (pp. 185-196). Abingdon, UK: Routledge.

Miles, M., \& Huberman, A. (1994). Qualitative data analysis (2nd Ed.). Thousand Oaks, CA: Sage Publications.

Morrison, E., Rudd, E., \& Nerad, M. (2011). Early careers of recent US social science PhDs. Learning and Teaching, 4(2), 6-29.

Neumann, A. (2006). Professing passion: Emotion in scholarship of professors at research universities. American Educational Research Journal, 43(3), 381-424.

Pearson, M., Cumming, J., Evans, T., Macauley, P., \& Ryland, K. (2011). How shall we know them? Capturing the diversity of difference in Australian doctoral candidates and their experiences. Studies in Higher Education, 36(5), 527-542.

Pilbeam, C., \& Denyer, D. (2009). Lone scholar or community member? The role of student networks in education in a UK management school. Studies in Higher Education, 34(3), 301-318.

Pole, C. (2000). Technicians and scholars in pursuit of the PhD: Some reflections on doctoral study. Research Papers in Education, 15(1), 95-111.

Riessman, C. (2008). Narrative methods for the human sciences. Los Angeles, US: Sage.

Sfard, A., \& Prusak, A. (2005). Telling identities: In search of an analytic tool for investigating learning as a culturally shaped activity. Educational Researcher, 34(4), 14-22.

Thomson, R., \& Holland, J. (2003). Hindsight, foresight and insight: The challenges of doing longitudinal qualitative research. International Journal of Social Sciences Methodology, 6(3), 233-244.

Timmerman, B., Feldon, D., Maher, M., Strickland, D., \& Gilmore, J. (2013). Performance-based assessment of graduate student research skills: Timing, trajectory, and potential thresholds. Studies in Higher Education, 38(5), 693-710.

Walsh, E. (2010). A model of research group microclimate: Environmental and cultural factors affecting the experiences of overseas research students in the UK. Studies in Higher Education, 35(5), 545-560.

\section{Biographies}

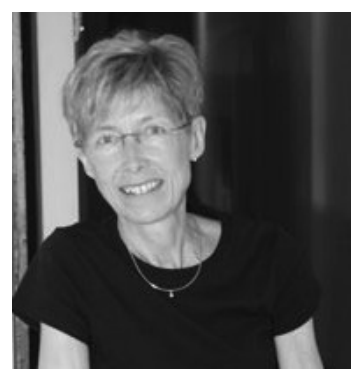

Lynn McAlpine is Professor of Higher Education Development at the University of Oxford and Professor Emerita at McGill University. Her current research is directed at understanding how doctoral students, post-PhD researchers and newly-appointed lecturers engage in and learn to do academic work - or choose to leave.

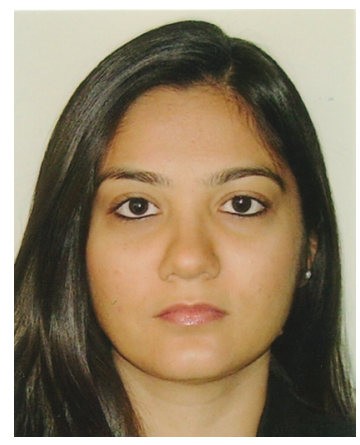

Mahima Mitra is a doctoral candidate in Social Policy at the Department of Social Policy and Intervention, University of Oxford. She has previously worked as a Research Assistant at the Oxford Learning Institute. Her research interests span policy research in the fields of education and family welfare particularly in developing country contexts, as well as health and higher education policy from an internationalcomparative perspective. 


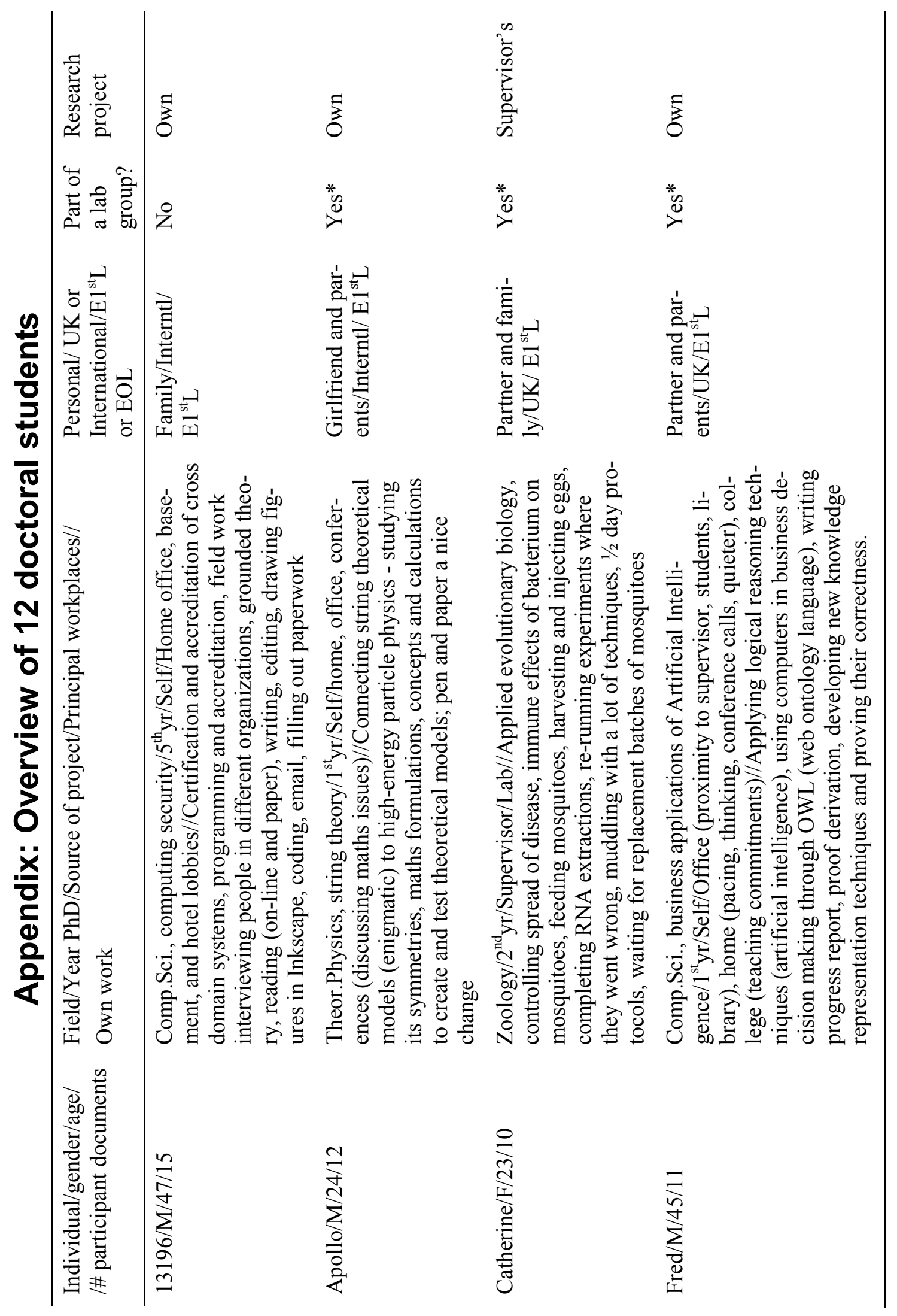




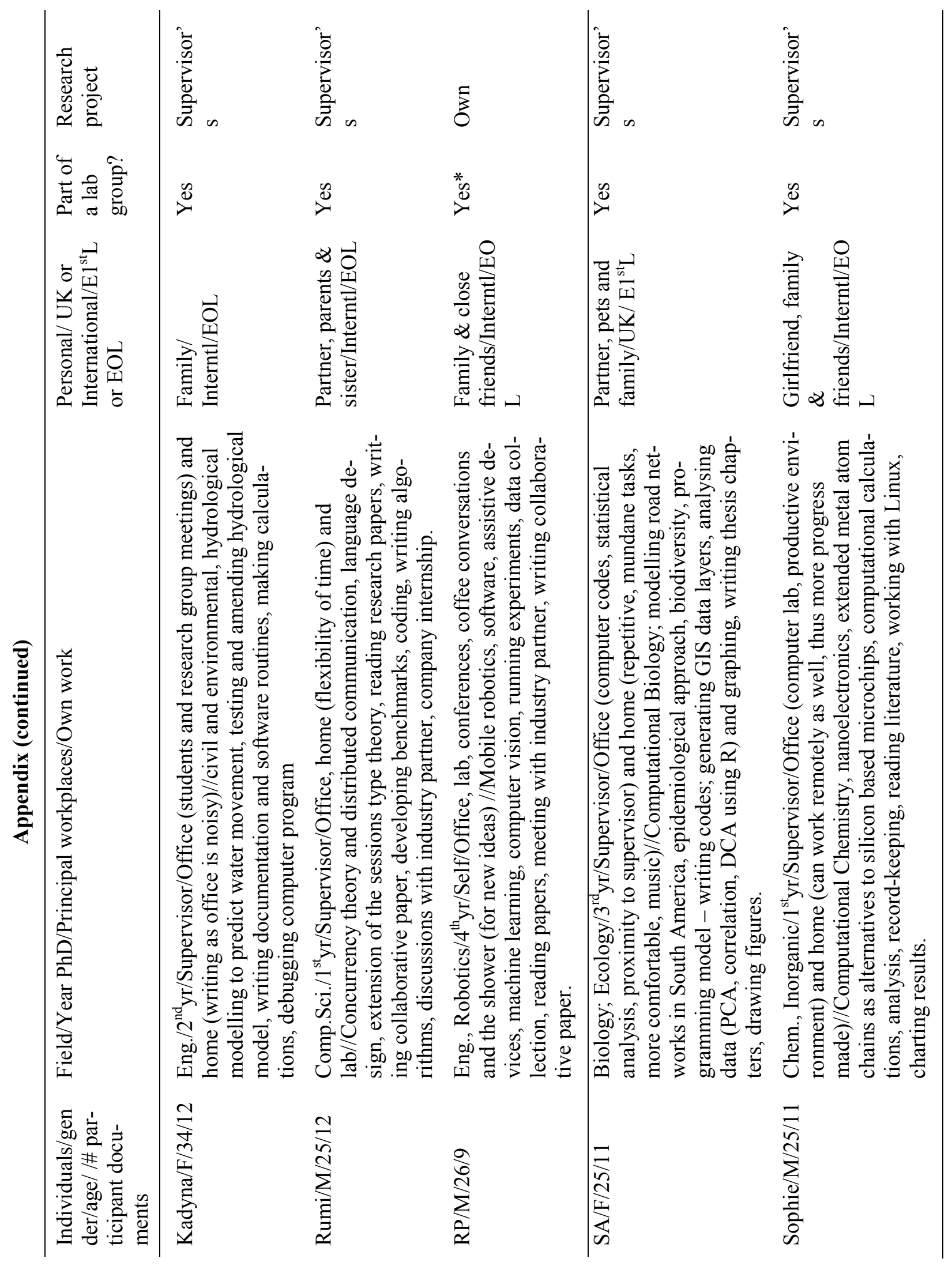




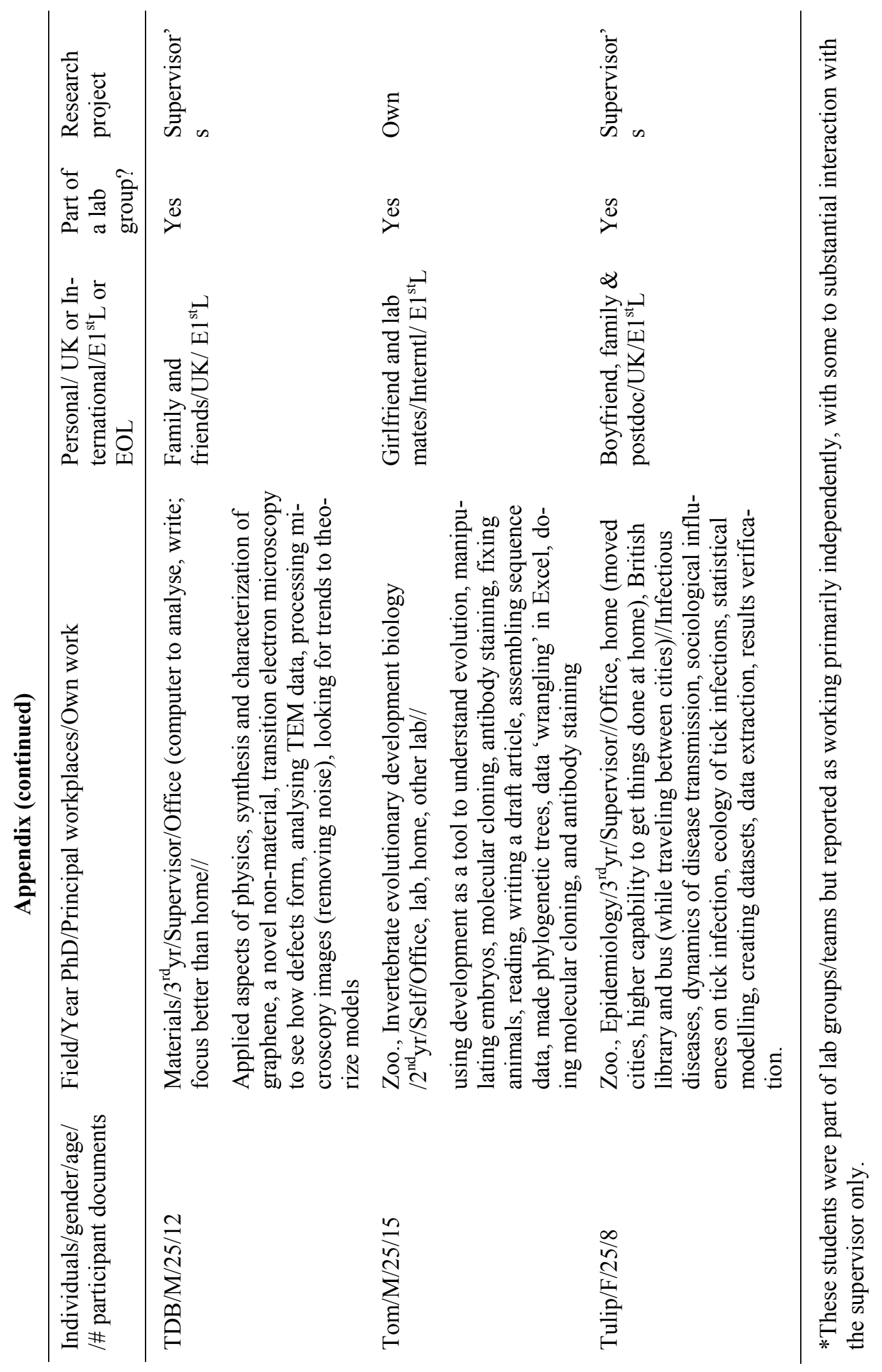

